\title{
Tests of the acoustic emission of the power steering column equipped with a modified composite worm gear housing
}

\author{
Marek Placzek $^{1}$, Andrzej Wróbel ${ }^{2}$, Mateusz Czechowski ${ }^{3}$, Andrzej Baier ${ }^{4}$ \\ Silesian University of Technology, Faculty of Mechanical Engineering, Institute of Engineering Processes \\ Automation and Integrated Manufacturing Systems, Gliwice, Poland \\ Nexteer Automotive Poland sp. z o.o., Tychy, Poland \\ ${ }^{1}$ Corresponding author \\ E-mail: ${ }^{1}$ marek.placzek@polsl.pl, ${ }^{2}$ andrzej.wrobel@polsl.pl, ${ }^{3}$ mateusz.czechowski@nexteer.com, \\ ${ }^{4}$ andrzej.baier@polsl.pl
}

Received 17 February 2018; accepted 25 February 2018 DOI https://doi.org/10.21595/vp.2018.19753

Check for updates

\begin{abstract}
Paper presents results of the laboratory tests concerning with measurements of the acoustic emission of the power steering column equipped with a modified composite gear body juxtaposed with the production version of the power steering column with the gear body made of aluminium alloy. The new, developed power steering column worm gear housing is made of a polymer called polydicyclopentadiene (PDCPD) and the Reaction-Injection-Moulding technology was used to produce it (the shortcut of the technology name is RIM technology). Both types of the worm power steering housings were tested to analyse their properties of acoustic emission. Results of the tests are very important considering noise generated during exploitation of a car's power steering system.
\end{abstract}

Keywords: acoustic emission, vibrations, measurements, RIM technology, car's power steering systems.

\section{Introduction}

Automotive industry is one of the main elements of the global industry. It is characterised by a very dynamic development and a high competitiveness. New versions of each car model are introduced to the market every few years and it is expected that the newer version will has better properties of exploitation than the previous one. This is why applications of new materials and new technologies of production are very important to achieve a high technological level and to be competitive. The implementation of new technologies and materials into all kinds of technical devices is a mean key of the global industry development because they open new doors and possibilities for designers and engineers $[1,2]$. It causes the possibility to achieve technical means that are for example cheaper and more effective [3-5].

The Reaction-Injection-Moulding technology (the RIM technology) of production of elements of technical devices brings new possibilities in this field. By application of this technology it is possible to achieve polymers with a high quality and very good parameters. The main benefits brings by implementation of such elements are their resistance for chemical agents and aging resistance as well as low water absorption. The main benefit of the technology is that low value of the injection pressure can be used what causes lower costs of production, including lower moulds costs.

In the automotive industry the possibility to design, produce and introduce new elements of the cars in a cheaper and faster way is a great advantage. The minimization of production cost is very important but on the other hand, such purposes as reduction of weight or reduction of vibration generated by the system during its exploitation are also aims of automotive industry [6-8].

The analysis of the possibility to achieve all of those purposes in the case of the power steering system of the car it is a very important issue in this light. In the presented research project, the possibility of introduction the PDCPD material and RIM technology of cold-injection for 
production of the worm gear housing using in the power steering system is considered. The standard, production version of the housing is made of aluminium alloy using hot-injection technology [6-8]. In the presented paper the comparison of power steering columns with both mentioned types of worm gear housing are presented. The first one is the power steering column with the standard, production version of the housing, while the second one is equipped with the developed housing made of PDCPD. The tests that aim was to verify acoustic emission of both types of the considered systems were carried-out. It should be also mentioned, that introduction of the PDCPD worm gear housing brings new possibilities of implementation of smart materials, for example piezoelectric transducers into its structure and create smart, mechatronic structures $[1,2,10,11]$. For example, while using the polydicyclopentadiene polymer and RIM technology, non-classical piezoelectric transducer could be implemented into the power steering housing to create a smart structure that could be able to damp vibration or control the technical conditions of the system.

\section{Analysed elements and carried out measurements}

In the carried-out research works the power steering column was considered. It is an element of the steering system of a passenger car. This element has a very important function in the steering system and has an influence on the comfort of the car's exploitation as well as the safety of the passengers. In Fig. 1. elements of the passenger car's power steering system are presented. In presented tests the power steering column (b) was considered, while the standard gear housing (c) was replaced by the housing made of polydicyclopentadiene polymer (PDCPD) [6-8].

As part of the research works, tests were carried out on the acoustic emission generated during the operation of the power steering column with the composite body. The research was carried out at the headquarters of Nexteer Automotive Poland in Tychy. Tests were carried out in accordance to the procedure of the radiated sound power and structure borne vibration forces measurement of column electric power steering stems procedure. The main purpose of the work was to objectively quantify the noise, vibration and harshness $(\mathrm{NVH})$ performance of column mounted electric power steering (CEPS) system and to compare this performance to NVH specifications and tolerance limits. Tests were performed in agreement with ISO 3744:1994 international standard titled: "Acoustics- Determination of sound power levels of noise source using sound pressureEngineering method in an essentially free field over a reflecting plane".

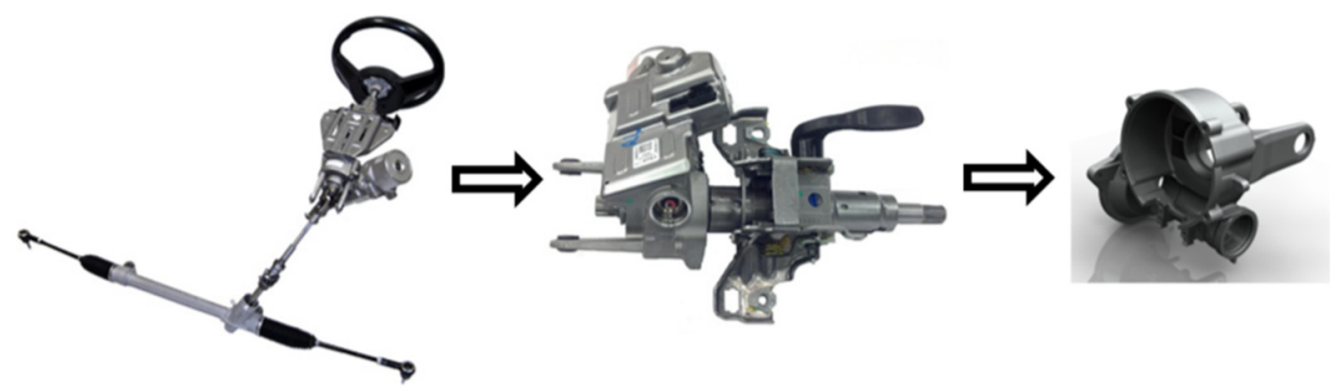

Fig. 1. Elements of the electric power steering systems: a) general overview of the system, b) power steering column, c) worm gear housing

In Fig. 2 a view of the laboratory stand located in Nexteer Automotive Poland headquarters during the conducted tests of the acoustic emission level of the power steering column is presented. Fig. 3 shows the views of power steering gears: standard and equipped with a composite housing of the worm gear during laboratory tests. On the laboratory stand force, torque and output shaft speed measurements are acquired simultaneously with the sound pressure measurements using the microphone array. 


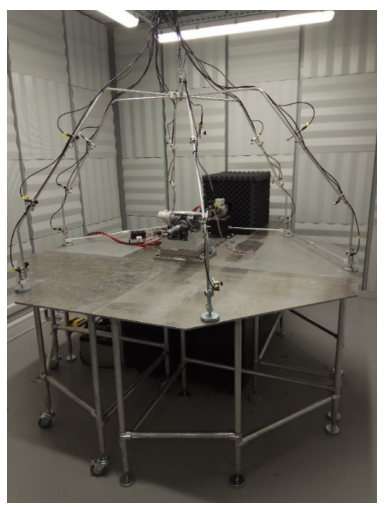

Fig. 2. View of the laboratory stand during conducted tests of the acoustic emission level of the electric power steering column

Tests were done using tri-axial force dynamometer, output shaft torque sensor and microphone array. The microphone array was configured in the hemispherical pattern utilizing 19 microphone positions. The distance between the tested unit and the microphone was one meter. Tests were carried out while the power steering column was loaded with the torque of 15,30 and $45 \mathrm{Nm}$, respectively, in case of turning in both directions (clockwise and counter clockwise). In addition, the behaviour of both types of power steering columns with electrical assistance was tested when operating at speeds of 30 and $60 \mathrm{rpm}$.

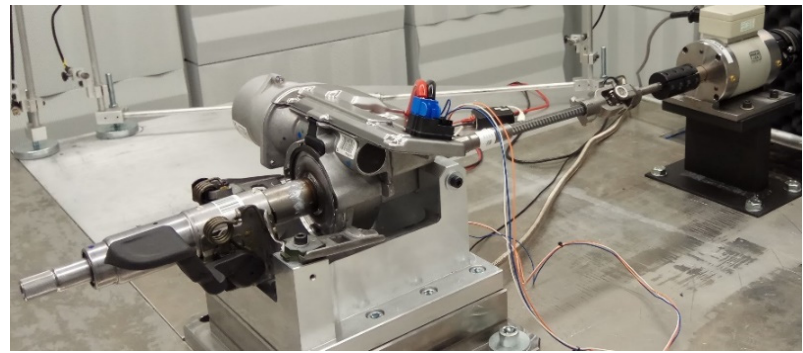

a)

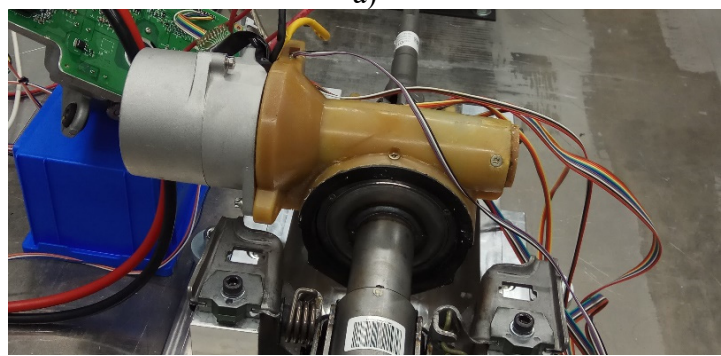

b)

Fig. 3. The standard a) and modified electric power steering column with composite housing of the worm gear b) during laboratory tests

\section{Obtained results}

Fig. 4 presents results of Fast Fourier Transform (FFT) analysis of signals registered with microphones number 1 and 2, respectively in the case of power steering column with a modified, composite worm gear housing (a) and a standard worm gear with an aluminium housing (b). These are the graphs obtained during the operation of the power steering column under a load of $15 \mathrm{Nm}$ at a speed of $30 \mathrm{rpm}$ counter-clockwise. 


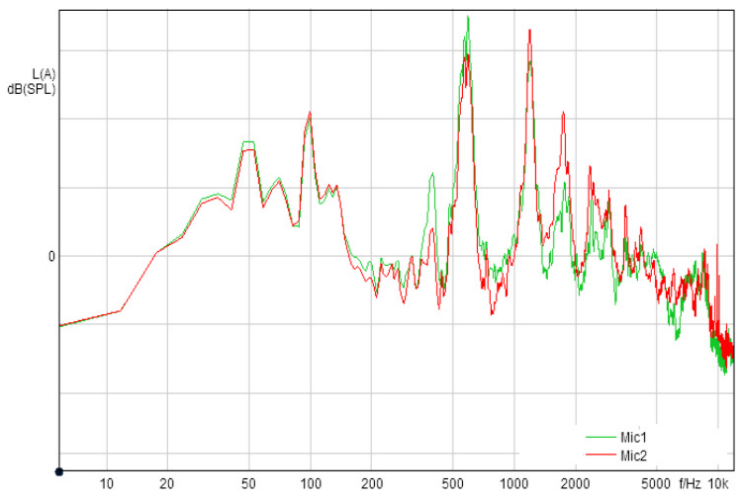

a)

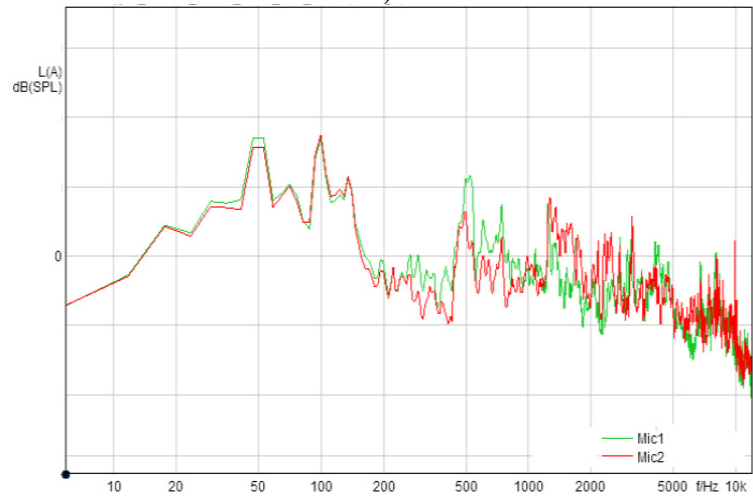

b)

Fig. 4. The result of FFT analysis of signals registered with microphones 1 and 2 in the case of a power steering column with a composite gear housing a) and a standard column with an aluminium gear housing b); (15 Nm, $30 \mathrm{RPM}, \mathrm{CCW})$

On the Fig. 5 results of the Fast Fourier Transform (FFT) analysis of the measured signals during the operation of the power steering column under a load of $45 \mathrm{Nm}$ at a rotational speed of $60 \mathrm{rpm}$ in the clockwise direction are presented. Values on the vertical axis were deliberately removed due to the manufacturer's lack of consent to disclose data on the numerical values of the power steering column's work parameters. Obtained characteristics are presented in the same scale to juxtaposed values of the standard and modified power steering column.

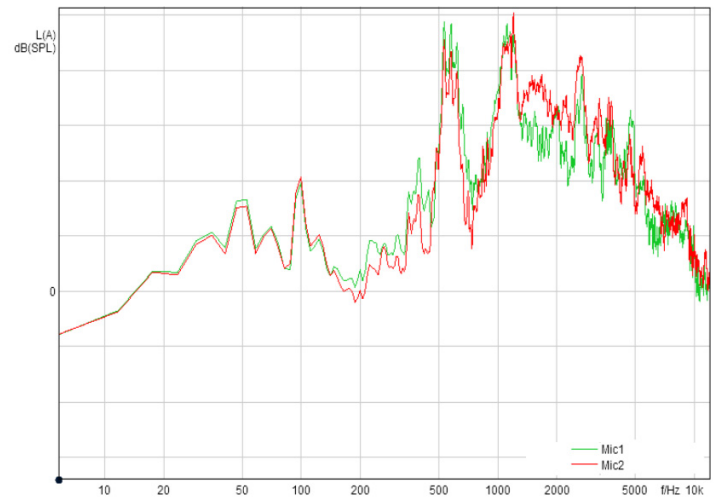

a) 


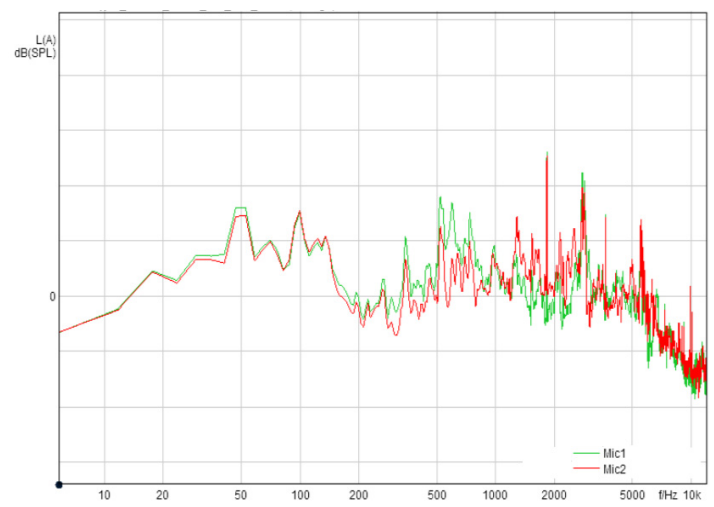

b)

Fig. 5. The result of FFT analysis of signals registered with microphones 1 and 2 in the case of a power steering column with a composite gear housing a) and a standard column with an aluminium gear housing b); (45 Nm, $60 \mathrm{RPM}, \mathrm{CW})$

\section{Conclusions}

In results of both presented measurements, a higher level of measured signals can be clearly observed in the case of power steering column with the modified, composite housing of the worm gear in relation to the standard one. It should be emphasized, however, that tests were carried out on a power steering column with a composite body, which was made according to the proposed production technology as the first prototype. Because of that it had some disadvantages, such as misalignment of the worm ad the shaft in the worm gear. These defects caused excessive acoustic emission during transmission operation. The research will be continued using next generations of a modified power steering column with a composite housing of the worm gear. Results of this work will be presented in the future publications. Considering previous tests of the vibration damping parameters of the worm gear housing made of polydicyclopentadiene polymer (PDCPD) presented in paper [7] it is predicted to obtain acceptable acoustic emission level.

The proposed introduction of the PDPCD material and RIM technology of production causes that many research works and tests must be conducted to verify the proposed solution and to be sure that it will be able to provide good parameters of exploitation and safety to the passengers of the car equipped with this solution. The introduced modification could have an important influence on vibration forms and frequencies of natural vibrations of the developed housing and as a result of that on the acoustic emission level. Therefore, presented tests are very important step on the design and construction process of the modified version of the system.

\section{Acknowledgements}

This work has been conducted as a part of research Project PBS3/B6/37/2015 (PST-41/RMT2/2015) in 2015-2018.

\section{References}

[1] Placzek M., Buchacz A., Wróbel A. Use of piezoelectric foils as tools for structural health monitoring of freight cars during exploitation. Eksploatacja i Niezawodnosc - Maintenance and Reliability, Vol. 17, Issue 3, 2015, p. 443-449.

[2] Placzek M. Conception of the system for traffic measurements based on piezoelectric foils. Materials Science and Engineering, Vol. 145, 2016, p. 42025.

[3] Jamroziak K., Bocian M., Kulisiewicz M. Energy consumption in mechanical systems using a certain nonlinear degenerate model. Journal of Theoretical and Applied Mechanics, Vol. 51, Issue 4, 2013, p. $827-835$. 
[4] Klarecki K., Rabsztyn D., Hetmanczyk M. Analysis of pulsation of the sliding-vane pump for selected settings of hydrostatic system. Ekspolatacja i Niezawodnosc - Maintenance and Reliability, Vol. 17, Issue 3, 2015, p. 338-344.

[5] Zolkiewski S. Testing composite materials connected in bolt joints. Journal of Vibroengineering, Vol. 13, Issue 4, 2011, p. 817-822.

[6] Baier A., Herbuś K., Ociepka P., Placzek M. Modal analysis in relation to the casing of an electric power steering system. Materials Science and Engineering, Vol. 227, 2017, p. 12010.

[7] Placzek M., Wróbel A., Baier A. Comparison of vibration damping of standard and PDCPD housing of the electric power steering system. Materials Science and Engineering, Vol. 227, 2017, p. 12095.

[8] Dimonie D., Dimonie M., Stoica S., et al. Some aspects of the thermal stability of linear polydicyclopentadiene (L-PDCPD), Polymer Degradation and Stability, Vol. 67, 2000, p. 167-170.

[9] Wróbel A., Placzek M., Buchacz A., Majzner M. Study of mechanical properties and computer simulation of composite materials reinforced by metal. Journal Materials and Product Technology, Vol. 50, Issues 3-4, 2015, p. 259-275.

[10] Tuma J., Simek J., Skuta J., et al. Active vibration control of hydrodynamic journal bearings. Springer Proceedings in Physics, Vol. 139, 2011, p. 619-624.

[11] Bialas K., Buchacz A., Galeziowski D. Comparison of active and semi-active damping in synthesis of various mechatronic discrete systems. Journal of Materials and Product Technology, Vol. 50, Issues 3-4, 2015, p. 340-355. 